\title{
Work, Recovery Activities, and Individual Well-Being: A Diary Study
}

\author{
Sabine Sonnentag \\ University of Konstanz
}

\begin{abstract}
This study extends previous research on respite from work and addresses the question of how individuals use their leisure time to recover from work. It is hypothesized that time spent on work-related and household activities has a negative effect on well-being, whereas low-effort, social, and physical activities are assumed to have a positive effect. One hundred Dutch teachers completed a diary on leisure time activities and situational well-being for 5 days, and work situation variables were assessed with a questionnaire. Multilevel analyses in which preleisure well-being and work situation variables were entered as control variables supported 4 of the 5 hypotheses. Moreover, a lagged effect of high time pressure on poor situational well-being was found. The study showed that leisure time activities and a low-stress work situation contribute independently to an individual's well-being.
\end{abstract}

Within work and organizational psychology, there is broad empirical evidence that stressful work situations, including high work demands and low control, are related to poor individual health and wellbeing (Danna \& Griffin, 1999; Ganster \& Schaubroeck, 1991; Kahn \& Byosiere, 1992; Lee \& Ashforth, 1996; Van der Doef \& Maes, 1999). Nevertheless, the amount of variance in individual health and well-being attributable to work situation variables is relatively small (Semmer, 1996; Zapf, Dormann, \& Frese, 1996) and does not exceed 10\% in most studies. To arrive at a better explanation of individual health and well-being, one must integrate additional variables in studies on the effects of work-related stress. Research suggests that individuals respond to a stressful work day with specific behaviors during their leisure time that help to alleviate the negative impact of stress experienced at work (Repetti, 1989).

The present study examined whether specific activities pursued during leisure time have an effect on individuals' well-being. I focused on individuals' situation-specific well-being before going to sleep and investigated whether the effects of leisure time activities existed beyond the possible effects of the

I am very grateful to $H$. Kodde, M. Jansen, and D. Zonneveld for their involvement and enthusiasm during data collection. Additionally, I thank H. Akli and K. Bühler for their helpful comments on earlier versions of this article.

Correspondence concerning this article should be addressed to Sabine Sonnentag, Department of Psychology, University of Konstanz, Postbox D42, D-78457 Konstanz, Germany. Electronic mail may be sent to sabine.sonnentag@ uni-konstanz.de. work situation and the effects of an individual's well-being at the end of the work day.

\section{Theoretical Models}

Theoretical models such as the effort-recovery model (Meijman \& Mulder, 1998) and the conservation of resources theory (Hobfoll, 1998) suggest that recovery and unwinding processes play an important role in predicting individual health and well-being. More specifically, the effort-recovery model (Meijman \& Mulder, 1998) describes that spending effort during working leads to specific load reactions in the individual. These load reactions include physiological, behavioral, and subjective responses. Under normal conditions, these reactions are reversible; that is, when an individual is no longer confronted with the work demands, his or her psychobiological systems previously affected by the demands return to their predemand level and recovery occurs. As a result of the recovery process, fatigue and other effects of stressful situations are reduced. However, when demands do not cease but are continuously put on the individual, no recovery can occur. As a consequence, load reactions accumulate and result in longer term negative effects, such as impaired well-being and health problems.

Thus, for recovery to occur, it is necessary that the demands previously put on the individual's psychobiological systems are removed and that the individual engages in a below-baseline activity (i.e., below baseline with regard to the respective previous demands; Craig \& Cooper, 1992). For example, imagine an individual whose work requirements put sub- 
stantial demands on his or her cognitive functional system. To recover from work, this individual will need to engage in an activity that puts only very low demands on his or her cognitive functional system. According to this model, relatively high physical demands will not impede this individual's recovery process.

The conservation of resources theory (Hobfoll, 1998) assumes that people strive to obtain, retain, and protect their resources. According to this theory, stress occurs when an individual's resources are threatened or lost or when no resources are gained after resource investment. In this context, resources are "objects, personal characteristics, and energies that are either themselves valued for survival, directly or indirectly, or that serve as a means of achieving these resources" (Hobfoll, 1998, p. 45). Applied to the context of work, the conservation of resources theory implies that an unfavorable work situation threatens or even harms an individual's resources, such as well-being, health, and functioning in other life domains. For example, during the process of working long hours, vigor decreases whereas tension and fatigue increase. Subsequently, individuals will strive to restore their resources. To restore one's resources, one must invest additional resources in oneself. Time periods during which one can draw on other resources (e.g., additional time, social support) offer the opportunity to restore one's resources.

Taken together, the effort-recovery model and the conservation of resources theory propose two complementary processes by which individual well-being benefits from time spent outside the job: The effortrecovery model suggests that refraining from work demands allows recovery processes to occur; conservation of resources theory suggests that time off the job allows for restoring lost or threatened resources by investing other resources. It is crucial in both models that resources needed during work are not further called on during time periods when recovery is supposed to occur. Situations such as work breaks, nonwork time during the evening or in the weekend, and vacations offer opportunities for such recovery processes and the restoration of threatened or lost resources.

\section{Previous Empirical Research}

Empirical research showed that time is needed to recover from work demands. For example, Totterdell, Spelten, Smith, Barton, and Folkard (1995) found that individuals' well-being tends to improve with an increasing number of rest days since the last work day. Similarly, a growing body of literature suggests that vacations and other off-job time function as a respite during which resources are restored and recovery occurs (Etzion, Eden, \& Lapidot, 1998; Westman \& Eden, 1997). For example, Westman and Eden (1997) found that the burnout level of clerical employees decreased during a 2 -week summer vacation, that is, during a time period in which individuals could spend replenishing their resources. Etzion et al. (1998) reported that during a military service (i.e., time spent off the job), burnout levels of male engineers and technicians decreased, particularly in men who experienced high detachment from their regular jobs. This finding suggests that it is not primarily pleasant activities such as those pursued during vacations that are important for recovery to occur. The availability of time periods that allow for the restoration of resources called on during regular work seems to be crucial. However, previous research on recovery processes did not address the issue of whether specific activities pursued during these time periods contribute particularly to an individual's well-being after off-work periods. Little is known about specific activities that help in recovering from work demands.

Studies from leisure sciences promise to contribute to our knowledge about recovery processes. Empirical research on leisure activities reported substantial relationships between specific activities pursued during leisure time and an individual's health and wellbeing (Stanton-Rich \& Iso-Ahola, 1998; Veenhoven, 1984). Particularly, social and physical activities were found to be associated with health and wellbeing. However, these studies on leisure time activities did not look at the joint effects of work situation variables and recovery activities. Therefore, conclusions to be drawn from the existing literature are somewhat limited. First, one's work situation might have an impact on both one's well-being and one's leisure time activity (Karasek \& Theorell, 1990; Kirkcaldy \& Cooper, 1993). Thus, it cannot be ruled out that the relationship between leisure time activities and well-being is attributable to one's work situation as a third variable. Second, so-called aftereffects of work (Frankenhaeuser, 1981) may interfere with recovery activities or mask the effects of leisure time activities. In this context, after-effects refer to strain effects of a stressful work day that do not unfold immediately but later, for example, during the evening hours at home. Moreover, most studies looked at cross-sectional relationships between specific leisure activities and individual mood and wellbeing. However, relatively little is known whether 
such activities can bring about changes in one's mood and well-being after a work day.

\section{Effects of Leisure Time Activities on Well-Being}

Well-being is a broad concept that includes a variety of affects and aspects of satisfaction and mental health (Diener, Suh, Lucas, \& Smith, 1999; Warr, 1990). It refers to global and rather stable evaluations of one's life and context-specific aspects as well as to momentary mood (Diener et al., 1999). When studying the effects of leisure time activities that occur within the time frame of several hours, one must focus on well-being at specific moments and in specific situations (e.g., well-being before going to sleep). Situational well-being is an overall evaluation of one's present state. Situational well-being before going to sleep can be conceptualized as an indicator that recovery is occurring.

Empirical research and people's daily experiences show that individuals cannot spend all the time outside their workplace on activities that have a recovering effect (Kleiber, Larson, \& Csikszentmihalyi, 1986; Leitner \& Leitner, 1989; Lundberg, Marberg, \& Frankenhaeuser, 1994). Besides personal maintenance activities, such as sleeping, eating, and personal hygiene, individuals have to engage in activities with a high-duty profile, such as additional jobrelated and household activities. Nevertheless, most individuals' time budgets include time to be spent on leisure activities, such as meeting with friends, watching a movie, or doing sports (Leitner \& Leitner, 1989; Robinson, 1999).

\section{Effects of Leisure Time Activities With a High-Duty Profile}

Activities with a high-duty profile refer to tasks an individual has to accomplish. These activities include (a) job-related activities such as finishing a task for one's job or preparing for the next work day, (b) task-related activities that refer to one's private life such as completing one's tax declaration, and (c) household and child-care activities. It is typical for such activities with a high-duty profile to be linked to a specific degree of obligation. They can be skipped or postponed only within relatively narrow margins.

Job-related activities draw on the same resources as task accomplishment processes during (formal) working time. Recovery, however, occurs only in situations in which no further demands are put on functional systems asked for during working time. Therefore, one can assume that spending time on job-related activities during leisure time will have a negative effect on an individual's situational wellbeing. A similar argument applies to most of the other task-related activities, which are often cognitively demanding activities. Particularly in jobs with high cognitive and high concentration requirements, spending time on other task-related activities will impede recovery to occur and will have a negative impact on an individual's situational well-being.

Hypothesis 1 . The amount of time spent on job-related and other task-related activities is negatively related to an individual's situational well-being before going to sleep.

Household and child-care activities require other resources than those needed for accomplishing most job-related duties (exceptions are some specific occupations such as cleaning or child care). Therefore, one could assume that household and child-care activities offer the opportunity to recover from jobrelated demands and associated strains. However, household and child-care activities in themselves are demanding; they require effort and draw on one's resources (Grandey \& Cropanzano, 1999; Mardberg, Lundberg, \& Frankenhaeuser, 1991). Most important, these activities are associated with a high degree of obligation and cannot be skipped without severe (in the case of child care) or at least unpleasant (in the case of housework) consequences. This implies that individuals must accomplish these tasks and spend effort and attention on them when already fatigued from the job. From the conservation of resources perspective (Hobfoll, 1998), the necessity to perform the task when tired and fatigued implies a threat of an individual's resources. Thus, one can assume that the demanding and obligatory nature of household and child-care activities exceeds their potentially beneficial effects. This implies that a large amount of time spent on household and child-care activities reduces an individual's well-being.

Hypothesis 2. The amount of time spent on household and child-care activities is negatively related to an individual's situational well-being before going to sleep.

\section{Effects of Leisure Time Activities With a Potential for Recovery}

The present study concentrates on three types of leisure time activities that have a potentially recovering effect: low-effort activities, social activities, 
and physical activities. All these activities differ from the job-related, household, child-care, and other taskrelated activities in that they are less obligatory and are often done for its own sake.

Typical low-effort activities are relatively passive activities such as watching TV, browsing through a magazine, or just relaxing on one's sofa (Kleiber et al., 1986). Often, these activities are characterized by a high degree of passivity, thus representing belowbaseline activities. This implies that no demands are put on resources normally required for accomplishing one's work tasks. As a consequence, the functional systems can return to their normal, prestressor level. Therefore, one can assume that low-effort activities have a recovery effect. Engaging in these activities will improve an individual's situational well-being.

However, some authors claim that passive leisure activities have a detrimental effect on individuals' health and well-being because they are related to boredom and apathy (e.g., Iso-Ahola, 1997). One could assume that this particularly applies to loweffort activities. However, some caveats are necessary. First, the conclusion that passive leisure has negative effects is largely derived from empirical findings that show the positive effects of active leisure (e.g., exercise and sports). However, this does not per se imply that spending some time on passive, that is, low-effort activities has the same negative effects as refraining from any active activity. One can imagine individuals who spend time both on active and on passive (i.e., low-effort) activities. Based on the effort-recovery model outlined above, one can assume that spending time on passive leisure adds to the prediction of well-being-beyond the assumed positive effect of active leisure activities.

Second, passive leisure might be a consequence of stressful and low-control work situations (Karasek \& Theorell, 1990). Such work situations are related to poor individual health and well-being. Thus, a correlation between passive leisure and poor health and well-being might be a spurious one that can be explained by third variables such as work situation variables. Additionally, depression might be a third variable that accounts for the relationship between passive leisure and poor well-being: Depressive individuals might engage more in passive leisure and at the same time suffer from poor well-being (Wells et al., 1989). Taken together, it cannot be ruled out that spurious relations account for the relationship between passive leisure and poor well-being. It is doubtful that time spent on low-effort activities causes poor well-being. The effort-recovery model rather suggests that low-effort, below-baseline activ- ities are necessary for an individual to recover and that these activities therefore have a positive effect on individual well-being.

Hypothesis 3. The amount of time spent on low-effort activities is positively related to an individual's situational well-being before going to sleep.

Social activities refer to activities that focus on social contact, such as meeting with family members, friends, and other individuals or groups. This category also includes activities such as going to a party, dining out with others, or phoning other people (see Palmore \& Luikart, 1972). There are two main mechanisms why social activities have the potential for being successful recovery activities. First, social activities offer the opportunity for social support. There is broad empirical evidence that social support has positive effects on well-being (Viswesvaran, Sanchez, \& Fisher, 1999). Empirical research on leisure activities point in the same direction. Hills and Argyle (1998) found that members of leisure groups experienced more positive affect than nonmembers (see also Iso-Ahola \& Park, 1996).

Second, during social activities, no further demands are put on resources needed during typical task-accomplishing processes. As a consequence, recovery processes can take place. One might argue that the situation is somewhat different for individuals in the customer service or educational domain who are faced with high requirements for social interaction during their working time. However, social interactions as work requirements put specific demands on the individual, particularly with respect to the regulation of one's feelings and observable expressions in line with the organizational goals (Grandey, 2000). Such a high degree of emotion regulation is not requested during most voluntary leisure time activities. Moreover, outside work, individuals have more choice with respect to their interaction partners than at work. They can decide to meet with those individuals who do not request demanding forms of emotion regulation. As a consequence, during social activities outside work, individuals working in the customer service or educational domain can experience a relief from the high degree of emotion regulation requested at their workplace. In other words, no further demands are put on the resources requested at the workplace, and recovery occurs. Thus, social activities are assumed to have a positive impact on individuals' situational well-being.

Hypothesis 4. The amount of time spent on social activities is positively related to an individual's situational well-being before going to sleep. 
Physical activities comprise a wide range of behaviors, including exercise, sport, and other activities such as walking and cycling. During physical activities, most individuals use other resources than those needed in work accomplishment processes, with the exception of individuals who work in the increasingly rare jobs with heavy physical demands. Active involvement in physical leisure activities implies a cognitive distraction of job-related duties (Yeung, 1996). A temporary relief from job-related problems and demands occurs that allows the functional systems to recover. Moreover, physical activities stimulate physiological and psychological processes, which contribute to an increase in individuals' health and well-being (Brown, 1990; Wankel \& Berger, 1990). Empirical research shows that physical activities have a positive effect on individuals' mood and well-being, including both short-term and long-term benefits (Brown, 1990; Byrne \& Byrne, 1993; Petruzzello, Landers, Hatfield, Kubitz, \& Salazar, 1991).

Hypothesis 5. The amount of time spent on physical activities is positively related to an individual's situational well-being before going to sleep.

\section{Work Situation and Well-Being at the End of the Work Day as Third Variables}

When examining the effects of recovery activities on situational well-being, one has to take into account that additional factors might have an impact on the situational well-being. Among these factors, the individual's well-being at the end of the work day and his or her work situation might play the most dominant role.

Situational well-being at the end of the work day refers to a person's affective state when leaving the workplace and returning home from work, irrespective of whether this state is caused by work-related or other factors. A person's situational well-being at the end of the work day might have an impact on the choice of leisure time activities (Dishman, Sallis, \& Orenstein, 1985; Kubey \& Csikszentmihalyi, 1990). Moreover, this person's situational well-being at the end of the work day might have an effect on his or her situational well-being before going to sleep. Thus, a relationship between specific leisure time activities and situational well-being before going to sleep might be attributable to the person's well-being at the end of the work day, as a third variable.

A person's work situation could have an impact on an individual's situational well-being before going to sleep through several mechanisms. First, the work situation can have an effect on a person's well-being at the end of the work day. For example, compared with individuals in highly stressful jobs, individuals in less stressful jobs feel better at the time when they leave their workplace. Then, the person's situational well-being at the end of the work day would have an impact on well-being before going to sleep. Stated differently, well-being at the end of the work day would be a mediator in the relationship between a person's work situation and his or her well-being before going to sleep. Second, a person's work situation might directly affect the choice of specific leisure activities (Karasek \& Theorell, 1990; Kirkcaldy \& Cooper, 1993). This would imply that a relationship between specific activities and situational well-being before going to sleep might be due to the person's work situation. Third, research suggests that stressful work situations can have aftereffects. Such after-effects are reflected not only in the immediate response to the work day as experienced directly after work (e.g., as poor situational wellbeing when returning home from work) but also in lagged effects that unfold during the hours after returning home from work (Frankenhaeuser, 1981; Meijman, Mulder, \& Van Dormolen, 1992). In other words, the work situation might have an effect on individual well-being before going to sleep, which is not completely mediated by individual well-being at the end of the work day.

To rule out such alternative explanations that draw on situational well-being at the end of the work day and the work situation as third variables, one has to control for these factors in the analysis. Moreover, the inclusion of work situation variables allows for the examination of the joint effects of work situation factors and leisure time activities, an approach that did not receive much attention in past research.

\section{Method}

\section{Sample}

The sample comprised 100 Dutch school teachers. There were several reasons why teachers were chosen as study group. First, compared with other employees, teachers have the option to spend more time outside their regular workplace. Thus, they have greater discretion in allocating time on various activities. This discretion was assumed to result in a greater variance of how time is spent on the various activities. Second, teachers have to accomplish part of their work tasks at home (e.g., preparing lessons for the next day, grading exams). This was a good precondition for testing Hypothesis 1 . Third, a relatively homogeneous sample was chosen to hold constant factors such as profession and type of tasks performed. Fourth, teachers have a relatively stress- 
ful job and experience poor well-being (De Heus \& Diekstra, 1999; Schaufeli, Daamen, \& Van Mierlo, 1994). For example, Schaufeli et al. (1994) compared Dutch teachers with a large representative sample of Dutch workers and a large sample of various human service workers. They found that teachers had significantly higher scores on psychological strain, somatic complaints, and emotional exhaustion. Thus, from a practical point of view, it is important to know which activities are helpful in recovering from work in such highly stressful jobs.

Recruiting of study participants began with the management of the schools being contacted. After the management expressed consent to participate, 150 teachers were approached through the schools' mailing systems and were asked to participate. A total of 100 teachers $(51$ male, 49 female) from four different school types participated in the study. These 100 teachers who completed the instruments represented an acceptable response rate of $67 \%$. Their mean age was 41.0 years $(S D=9.8)$. School types ranged from primary to grammar school. The majority of the participants (79\%) lived with a partner, $6 \%$ lived with another person who was not the partner, and $15 \%$ lived alone. In total, $62 \%$ of the participants had no children, $4 \%$ had one child, $15 \%$ had two children, $15 \%$ had three children, and $4 \%$ had four children. The study took place in the middle of the school year: $12 \%$ of the participants completed the instruments in December, $71 \%$ in January, $13 \%$ in February, and $4 \%$ in March or April.

The 100 participating teachers were compared with the population of all teachers employed in the Dutch educational system. Compared with the Dutch teachers' average age of 43.50 years, the participants in this study were slightly younger; the percentage of women in the study sample corresponded to the percentage of women among all Dutch school teachers (Ministerie van Onderwijs, 1999).

\section{Measures}

Data were gathered with a diary and a questionnaire method. All items were in Dutch. Participants filled in the questionnaire at the start of the study before they started to complete the diary.

Activities. Because retrospective reports about the engagement in specific activities may be of limited validity (Smith, Leffingwell, \& Ptacek, 1999; Stone et al., 1998) and because time devoted on specific activity categories may vary substantially during the week, activity data were gathered with a diary method. Participants completed the diary on 5 consecutive work days. Participants were provided with short descriptions of five activity categories and a list of prototypical activities within each category. The five activity categories included the following ${ }^{1}$ : (a) work-related activities, for example, finishing or preparing for work duties and doing one's private administration; (b) household and child-care activities, for example, cooking, doing the dishes, shopping, and taking care of the children; (c) loweffort activities, for example, watching television or taking a bath; (d) social activities, for example, meeting with others or making a phone call to chat; (e) physical activities, for example, sports, cycling, and dancing. Per day, participants had to report the time they started and ended each activity. In addition, they were asked to report the amount of time they spent on other activities falling in these categories but not mentioned in the list provided in the diary.
For data analyses, for every category and each day, the total time spent on all the activities in the specific category was computed. For more details about the diary method, see Sonnentag (2000).

Situational well-being. For assessing participants' situational well-being, I developed two short measures: (a) situational well-being at the end of the work day as control variable and (b) situational well-being before going to sleep as dependent variable. Both measures were assessed in the diary on the 5 consecutive days and were intended to assess an individual's state in a specific situation on each of the 5 days. Situational well-being at the end of the work day referred to participants' situational well-being when leaving their workplace and returning home. It was measured with three 5-point Likert-type items (e.g., "I felt tense when coming home from work" [reverse scored], "I was in a good mood when coming home from work," and "I was in a good mood at the end of the workday"). Cronbach's alphas coefficients were computed separately for the 5 days. They ranged between .70 and $.81(M=.76)$. Situational wellbeing before going to sleep was measured with three 5-point Likert-type items (e.g., "I felt tense before going to sleep" [reverse scored], "I was in a good mood before going to sleep," and "I feel that I have had enough time to relax and recover from my workday"). Cronbach's alphas ranged between .66 and $.78(M=.71)$. Participants provided the answers to both well-being measures before they went to sleep.

To examine the validity of these situational well-being measures, I assessed participants' well-being at the end of the 5-day period with an additional questionnaire. This questionnaire comprised the Dutch version (Schalk, Keunen, \& Meijer, 1995) of Warr's (1990) affective wellbeing measures: anxiety-contentment (Cronbach's $\alpha=$ .81) and depression-enthusiasm (Cronbach's $\alpha=.84$ ) based on the three-axes model of well-being (Warr, 1987). I regressed participants' anxiety-contentment scores and depression-enthusiasm scores on the 10 situational wellbeing scores of the respective participant ( 5 "at the end of the work day" measures and 5 "before going to sleep" measures). Multiple correlation was $R=.72(p<.001)$ for anxiety-contentment and $R=.70(p<.001)$ for depression-enthusiasm. This finding suggests that the short situational well-being measures tapped the core of the affective well-being concept

Work situation. Participants' work situation was assessed with three questionnaire measures: time pressure, uncertainty, and control at work. Time pressure and control at work refer to the two dimensions of the job demandcontrol model (Karasek \& Theorell, 1990), and uncertainty closely corresponds to role ambiguity (Kahn, Wolfe, Quinn, Snoek, \& Rosenthal, 1964). High time pressure, low control at work, and high uncertainty/role ambiguity are known to be related to poor individual well-being (Jackson \& Schuler, 1985; Spector, 1986; Wall, Jackson, Mullarkey, \& Parker, 1996). In the present study, time pressure, uncertainty, and control at work were measured with scales developed by

\footnotetext{
${ }^{1}$ In the diary, participants were asked about two additional activities (creative activities, such as painting or playing music, and further activities not covered by the other categories). These activities were not included in the analyses.
} 
Semmer (1984) and Zapf (1993): Time pressure was measured with 5 items referring to a high quantitative workload and high concentration demands (e.g., "I often work under time pressure"). Cronbach's alpha was .71. Uncertainty was measured with a short version of the scale comprised of 3 items (e.g., "I often get vague instructions from my coworkers or my supervisor"). Cronbach's alpha was .72 . The control at work measure comprised 7 items (e.g., "I can decide how I accomplish my work"). Cronbach's alpha was 83. Validity studies showed acceptable to good coefficients for the three scales (for a summary, see Semmer, Zapf, \& Dunckel, 1999).

\section{Data Analysis Procedure}

For each study participant, data on two levels were available: at the day level (activity and situational well-being data) and at the person level (work situation variables and demographic variables), with the day-level data being nested within the person-level data. Data were analyzed with multilevel analysis (i.e., a hierarchical linear modeling approach; Bryk \& Raudenbush, 1992). Hierarchical linear modeling is the most appropriate method for dealing with this kind of a hierarchically structured dataset and takes the dependence of the day-level measurements within each person into account (Snijders \& Bosker, 1999). More information about the hierarchical linear modeling procedure is given in the Appendix.

For data analysis, the MLn program was used (Rasbash \& Woodhouse, 1996). In these analyses, predictor variables at the person level (work situation variables and demographic variables) were Level 2 data and were centered around the grand mean. Predictor variables at the day level (situational well-being and activity data) were Level 1 data and were centered around the respective person mean.

Within multilevel analysis, it is possible to test and compare several models starting with a null model that includes only the intercept and does not specify any predictor variable. In the following steps, several predictor variables can be added consecutively (both at the day and the person level), and the improvement of one model above a previous one can be examined using a likelihood ratio statistic.

\section{Results}

Table 1 shows means, standard deviations, and zero-order correlations between the study variables. When appropriate, both day-level and person-level correlations are displayed.

\section{Test of Hypotheses}

For testing the hypotheses, I followed a hierarchical data analysis strategy and examined a number of nested models. In the null model, the intercept was the only predictor. In Model 1, demographic variables (sex, age, and number of children; Level 2) and situational well-being at the end of the work day (Level 1) were entered as predictors. In Model 2,

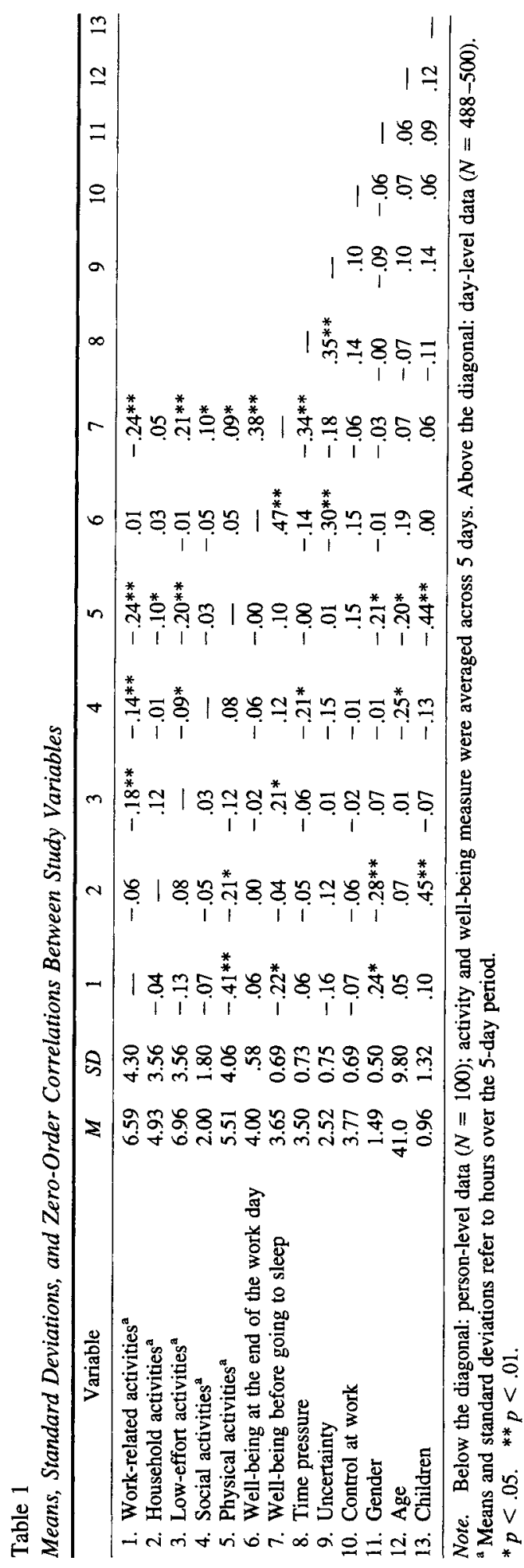


work situation variables (control at work, time pressure, and uncertainty; Level 2) were entered. Finally, in Model 3, the five activity variables (Level 1) were entered.

To test the improvement of each model above the previous one, I computed the difference of the respective likelihood ratios. This difference follows a chi-square distribution (with degrees of freedom $=$ number of new parameters added to the model). Results are shown in Table 2.

Analysis revealed that Model 1, which included demographic and situational well-being at the end of the work day, showed a significant improvement over the null model (difference of $-2 * \log =34.05, d f=4$, $p<.01$ ). Situational well-being at the end of the work day was the only but highly significant predictor in this model.

Compared with Model 1, Model 2 in which work situation variables were entered showed a significantly smaller likelihood ratio (difference of $-2 * \log =13.23, d f=3, p<.01)$. This indicates that work situation variables contributed significantly to the prediction of well-being before going to sleepbeyond the strong effects of well-being at the end of the work day. The predictive power of work situation variables was mainly based on the effect of time pressure. The higher an individual's time pressure at work, the poorer was this person's well-being before going to sleep, indicating an after-effect.

In Model 3, leisure time activities were included. Again, a significant improvement over the previous model (Model 2) resulted (difference of $-2 * \log =$ $54.37, d f=5, p<.01$ ). Inspection of regression coefficients showed that a high amount of time spent on work-related activities had a negative impact on an individual's well-being before going to sleep, whereas time spent on low-effort, social, and physical activities had a positive impact on well-being. Time spent on household activities had no effect. Taken together, Hypotheses 1, 3, 4, and 5 were supported by the data. The effects of leisure time activities existed beyond the effects of well-being at the end of the work day and the effects of work situation variables.

\section{Additional Analyses}

To explore the effects of recovery activities further, I performed additional analyses. ${ }^{2}$ First, I addressed possible interaction effects between work situation variables and recovery activities. More specifically, I tested whether there were leisure time activities that buffer the negative effect of time pres- sure on individual well-being. However, no such significant interaction effects were found. Second, I tested whether the combination of specific activities had an effect on well-being, particularly whether low-effort, social, or physical activities attenuate the negative effects of work-related activities and whether time spent on more active recovery activities (i.e., social and physical activities) enhances the positive effect of more passive activities (i.e., low-effort activities). None of the interaction terms turned out to be significant. Third, I examined whether the breadth of activities is related to an individual's situational well-being. I computed the breadth of activities as the number of categories out of which activities were performed (e.g., spending time just on social activities corresponded to a low breadth of activities, whereas spending time on job-related, social, and physical activities corresponded to a higher breadth of activities). I used this variable as a day-level predictor in multilevel modeling after having entered situational well-being at the end of the work day, the demographic variables, and the work situation variables. Analysis showed that the number of different activities an individual performed was positively related to his or her situational well-being before going to sleep (difference of $-2 * \log =4.03, d f=1, p<$ $.05)$. Fourth, I tested whether the activities performed on one day still have an effect on the following day; for example, an individual's well-being might suffer from extensive work-related activities on the previous day or it might benefit from low-effort activities on that day. I tested for such spillover effects with the same multilevel modeling procedures as described in the Method section and the Appendix, using the activities performed on the preceding day as predictors, instead of activities performed on the same day. Analysis did not reveal any spillover effect from one day to the next.

\section{Discussion}

This study examined the effects of activities performed during leisure time on situational well-being. Analysis showed that work-related activities had a negative effect on individuals' situational well-being before going to sleep, whereas low-effort activities, social activities, and physical activities had a positive effect. These effects existed beyond the strong effects

\footnotetext{
${ }^{2}$ More information about the additional analysis and tables summarizing the findings can be requested from the author.
} 


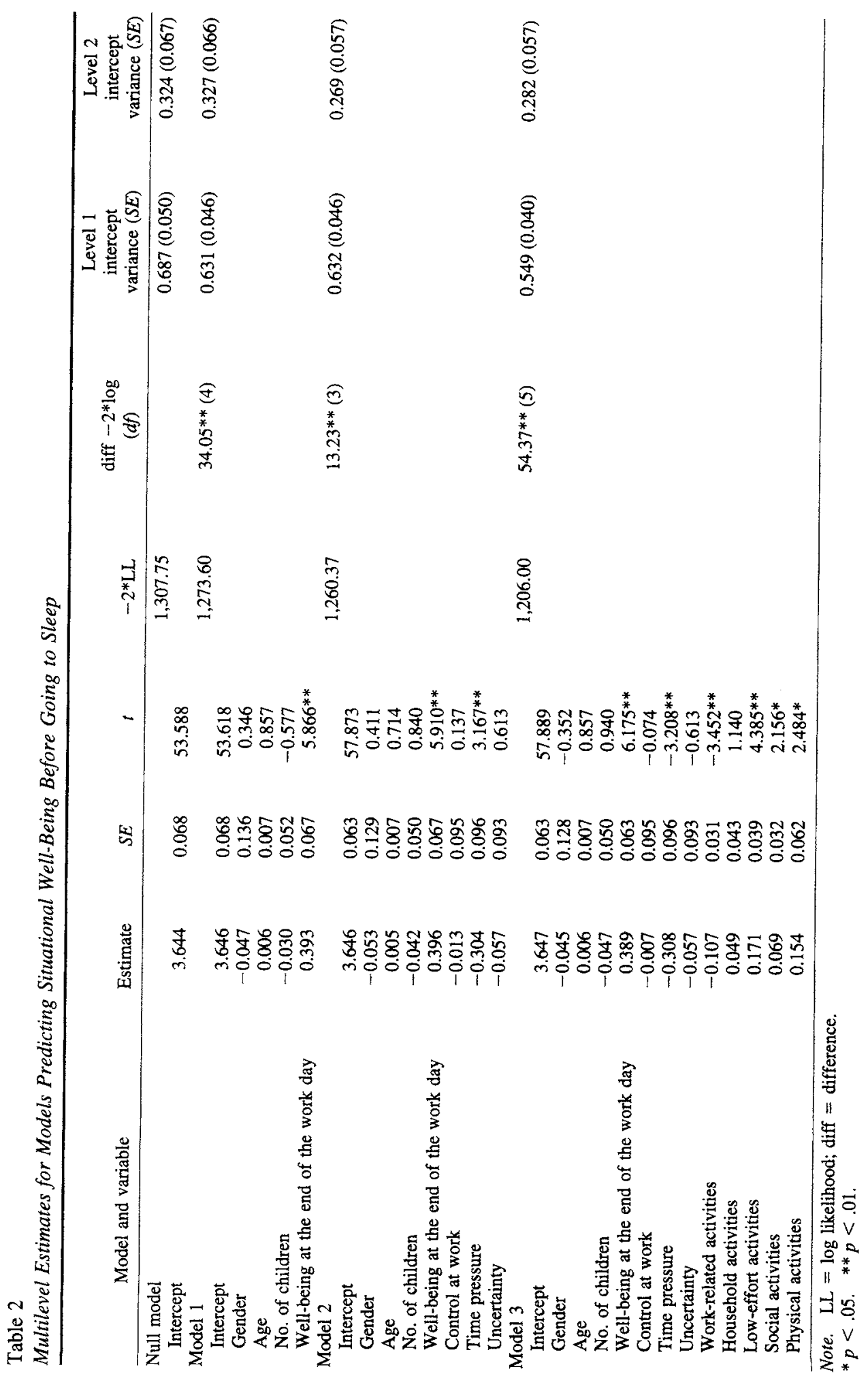


of individuals' well-being at the end of the work day. Moreover, an after-effect of time pressure at work on situational well-being was found. There was no effect of household and child-care activities on situational well-being.

The study extends previous research on respite from work (Westman \& Eden, 1997) and confirms findings from earlier research which showed that leisure time activities are related to individuals' wellbeing (Stanton-Rich \& Iso-Ahola, 1998; Veenhoven, 1984). More specifically, the positive effects of social and physical activities are in line with earlier findings (Brown, 1990; Byrne \& Byrne, 1993; Hills \& Argyle, 1998; Iso-Ahola \& Park, 1996). However, the positive effect of low-effort activities questions the assumption about the negative impact of "passive" leisure time activities (Iso-Ahola, 1997). Spending some time on activities that put overall low demands on the individual are experienced as helpful for arriving at a high level of well-being. This is at least true for individuals in stressful jobs such as the teachers studied here (Schaufeli et al., 1994). Moreover, it became evident that both active (e.g., physical) and passive (e.g., low effort) activities have positive effects on well-being. These findings and the relatively low intercorrelations between the various leisure time activities (see Table 1) suggest that it is not primarily the question of whether individuals engage in more active or more passive leisure time activities; both types of activities have beneficial effects.

Work-related activities turned out to have a negative impact on situational well-being. Thus, workrelated activities pursued at home seem to draw on the same resources as those needed to complete one's job. Moreover, engaging in job-related activities at home implies that one keeps thinking of one's job duties and associated problems. Spending time on job-related activities works against a cognitive distraction from one's job and therefore might impede recovery processes from occurring. This finding is particularly important in the face of recent developments that make the boundaries between work and nonwork time more and more permeable. The widespread use of technologies such as electronic mail, pagers, and mobile (cellular) phones enable-and sometimes require-individuals to stay in touch with work while at home. This implies that during time that should be devoted to leisure activities, individuals engage in work-related task. As a consequence, cognitive detachment from one's job and associated recovery processes cannot occur. The present study suggests that this has negative short-term effects on an individual's well-being. Future research should examine whether there might be negative long-term effects as well.

Household and child-care activities were not related to situational well-being before going to sleep. Thus, for the sample as a whole, all household and child-care activities together had neither an additional demanding nor a recovery effect. However, this does not exclude the fact that specific activities within this large category have a pronounced positive or negative effect on one's well-being. There might be particularly exhausting household activities, for example, doing the family's shopping for the whole week, which therefore have a negative impact on an individual's well-being. Similarly, some individuals might experience mainly positive effects of household and child-care activities, whereas others might experience mainly negative effects. Further studies are needed to examine the moderating effects of type of activities and individual characteristics.

Time pressure was found to have a significant after-effect on situational well-being before going to sleep when controlling for situational well-being at the end of the work day. This result suggests that the negative effects of time pressure experienced in the job mainly unfold during leisure time. Findings presented by Frankenhaeuser (1981) and Meijman et al. (1992) point in a similar direction. For example, Frankenhaeuser reported a study on adrenaline excretion rates during periods of high workload. Analysis showed that adrenaline excretion rates remained elevated during leisure time in the evening and even showed a higher increase, compared with periods of normal workload, than adrenaline excretion rates during the work day. The findings from the present study as well as from the earlier studies on after-effects of work demands indicate that an individual's functioning during leisure time is related to his or her experience during the work day.

An inspection of the zero-order correlations (see Table 1) shows only weak correlations between work situation variables and time spent on the specific leisure activities (the only exception was the significant negative correlation between time pressure and social activities). This finding seems to contradict the assumption of a relationship between workplace factors and types of leisure time activities (Karasek \& Theorell, 1990). However, it has to be noted that all of the participants in the present study were faced with relative similar job requirements, and therefore differences in leisure activities could not be explained by differences in the participants' work situation. As can be seen from Table 1, there were 
significant relationships between demographic factors and leisure time activities, particularly with respect to physical activities.

\section{Strengths and Limitations}

This study has some particular strengths and limitations. Leisure time activities were measured with a diary method. Therefore, the problems associated with the use of retrospective data for assessing activities over longer time periods were avoided (Smith et al., 1999; Stone et al., 1998). Data were assessed over a period of 5 days, substantially longer than the time period of 2 days normally covered by time budget research (Harvey, 1999). By covering a period of 5 days, this study took into account variations in activities and well-being across the days.

In the analysis, I controlled for demographic variables, work situation variables, and situational wellbeing at the end of the work day. The results show that the effects of specific leisure time activities can neither be explained by individuals' prior situational well-being nor be explained by their work situation. Rather, work situation and leisure variables independently contribute to the prediction of individual wellbeing. Thus, this study adds to prior studies that focused nearly exclusively on the effects of the work situation or the effects of leisure time activities.

Well-being at the end of the work day was measured retrospectively at bedtime. This is a clear limitation of the study. It might be that participants reported their well-being at the end of the work day in the light of their present, that is, bedtime, wellbeing. This implies that the relationship between well-being at the end of the work day and well-being before going to sleep might be inflated in the retrospective reports, therefore leaving less variance in well-being before going to sleep to be explained by leisure time activities. However, effects of leisure time activities were significant, despite the retrospective assessment of well-being at the end of the work day.

Another limitation of this study involves the relatively broad categories used for assessing leisure time activities. Therefore, effects of specific activities that might have worked into the direction opposite to their respective larger categories could not be detected. However, asking about more specific activities would have put additional strain on the study participants. Moreover, the question remains whether analyzing specific activities would change the overall picture. Rather, one might argue that specific activities do not have the same effects for all participants, thus, one might expect interaction effects.

Furthermore, one might question the generalizability of the findings. More specifically, one might argue that only teachers who felt they have enough time available to fill in the diary participated in the study, whereas others experiencing high time-consuming demands did not return the diary. This would imply that the sample included mainly individuals with low demands and that the study findings could not be generalized to individuals who face a high workload, be it in their job or in their private life. This argument cannot be ruled out completely. However, the overall return rate of $67 \%$ was relatively high. Additionally, participants who did return the diary also had to deal with time-consuming responsibilities. For example, more than a third of the sample had at least two children to take care of. These data suggest that the study findings are not biased by a highly selective sample.

This study is based on a sample of teachers. Teachers differ from other employees in that they have the option to spend more time outside their workplace, which gives them more discretion in allocating time among various activities. Additionally, teachers have to complete part of their job-related tasks at home. Therefore, the finding about the negative effects of work-related activities might be specific for a teacher's job. Clearly, studies are needed to test the generalizability of this study's findings on other occupational groups.

One further objection refers to the possible reactivity of the diary method. One might argue that individuals changed their leisure time behavior as a result of paying attention to and reporting their activities. However, in the present study, the measurement period was substantially shorter than in other studies that reported an effect of diary keeping on behavior and mood (e.g., Burt, 1994). Thus, it is not likely that diary keeping over a period of 5 days caused changes in the amount of time devoted on the activities.

\section{Directions for Future Research and Practical Implications}

This study focused on leisure time activities and recovery processes during the evenings of work days. But for leisure activities and recovery processes, weekends also play an important role. Therefore, future studies should examine the effects of activities pursued during the weekend. 
The sample included in this study had relatively regular working hours. However, there are increasingly more professional groups whose work situation is characterized by irregular working hours and shiftwork schedules (Spurgeon \& Cooper, 2000). Previous research has shown that irregular working hours and shift work have a negative impact on the opportunity to engage in specific leisure time activities (Knauth, Kiesswetter, Ottman, Karvonen, \& Rutenfranz, 1983). Future research should examine the effects of leisure time activities that are pursued by individuals with irregular working hours and shift workers.

In this study, amount of time spent on specific leisure time activities was the predictor variable. However, for recovery effects to occur, not only the amount of time but other features of the activities may be equally or even more important. For example, one might think of the degree of detachment from one's job or the experienced pleasantness of an activity. One might speculate that experiencing workrelated activities as extremely pleasant might attenuate their negative impact on well-being before going to bed. Similarly, experiencing social activities or physical activities as unpleasant might reduce these activities' positive effects on recovery.

This study examined the short-term effects of leisure time activities. Future studies should address the question of whether specific categories of leisure time activities have positive long-term consequences. Here, longitudinal studies that cover longer time periods are needed.

The present study showed the positive effect of specific leisure time activities. However, the study does not tell much about the necessary preconditions that must be present for individuals to initiate and perform these activities. With respect to practical implications, it will be particularly useful if future research examines the predictors of performing "successful" leisure time activities. For example, planning specific activities in advance or pursuing activities on a regular basis may help in starting these activities after coming home from work.

When it comes to more immediate practical implications, the findings should encourage individuals to maximize the time they spend on leisure time activities, such as low-effort, social, and physical activities. The study suggests that it is particularly helpful for an individual's well-being, and probably for recovery, to spend some time on low-effort activities. In our busy times, it might be even necessary to deliberately reserve some time for "doing nothing."

On the basis of the study findings, one would be advised to reduce work-related activities performed during leisure time to a minimum. Therefore, managers who allocate tasks to be accomplished during leisure time must be aware that this might be negative for their employees' well-being, which in turn may have a detrimental effect on subsequent performance (Staw, Sutton, \& Pelled, 1994). However, keeping leisure time free from work-related duties is not always feasible. Therefore, individuals should find ways to accomplish their work-related tasks efficiently. This will allow them to save time to be spent on "real" leisure time activities that have a positive effect on their well-being.

Moreover, additional analysis failed to find any interaction effect between time pressure and leisure activities on situational well-being. This implies that leisure time activities do not buffer the negative effects of a stressful work situation, although they have beneficial effects on their own. This clearly points to the need to reduce time pressure at the workplace and to enable individuals to better deal with time pressure when it occurs.

\section{References}

Brown, D. R. (1990). Exercise, fitness, and mental health. In C. Bouchard, R. J. Shephard, T. Stephens, J. R. Sutton, \& B. D. McPherson (Eds.), Exercise, fitness, and health: A consensus of current knowledge (pp. 607-626). Champaign, IL: Human Kinetics.

Bryk, A. S., \& Raudenbush, S. W. (1992). Hierarchical linear models: Application and data analysis methods. Newbury Park, CA: Sage.

Burt, C. D. B. (1994). Prospective and retrospective account-making in diary entries: A model of anxiety reduction and avoidance. Anxiety, Stress and Coping: An International Journal, 6, 327-340.

Byrne, A., \& Byrne, D. G. (1993). The effect of exercise on depression, anxiety and other mood states: A review. Journal of Psychosomatic Research, 37, 565-574.

Craig, A., \& Cooper, R. E. (1992). Symptoms of acute and chronic fatigue. In A. P. Smith \& D. M. Jones (Eds.), Handbook of human performance (Vol. 3, pp. 289-339). London: Academic Press.

Danna, K., \& Griffin, R. W. (1999). Health and well-being in the workplace: A review and synthesis on the literature. Journal of Management, 25, 357-384.

De Heus, P., \& Diekstra, R. F. W. (1999). Do teachers burn out more easily? A comparison of teachers with other social professions on work stress and burnout symptoms. In R. Vandenberghe \& A. M. Huberman (Eds.), Understanding and preventing teacher burnout: A sourcebook of international research and practice (pp. 269-284). Cambridge, England: Cambridge University Press.

Diener, E., Suh, E. M., Lucas, R. E., \& Smith, H. L. (1999). Subjective well-being: Three decades of progress. Psychological Bulletin, 125, 276-302.

Dishman, R. K., Sallis, J. F., \& Orenstein, D. R. (1985). The 
determinants of physical activity and exercise. Public Health Reports, 100, 158-171.

Etzion, D., Eden, D., \& Lapidot, Y. (1998). Relief from job stressors and burnout: Reserve service as a respite. Journal of Applied Psychology, 83, 577-585.

Frankenhaeuser, M. (1981). Coping with stress at work. International Journal of Health Services, 11, 491-510.

Ganster, D. C., \& Schaubroeck, J. (1991). Work stress and employee health. Journal of Management, 17, 235-271.

Grandey, A. A. (2000). Emotion regulation in the workplace: A new way to conceptualize emotional labor. Joumal of Occupational Health Psychology, 5, 95-110.

Grandey, A. A., \& Cropanzano, R. (1999). The conservation of resources model applied to work-family conflict and strain. Journal of Vocational Behavior, 54, 350-370.

Harvey, A. S. (1999). Guidelines for time use data collection and analysis. In W. E. Pentland, A. S. Harvey, M. P. Lawton, \& M. A. McColl (Eds.), Time use research in the social sciences (pp. 19-45). New York: Kluwer.

Hills, P., \& Argyle, M. (1998). Positive moods derived from leisure and their relationship to happiness and personality. Personality and Individual Differences, 25, 523-535.

Hobfoll, S. E. (1998). Stress, culture, and community: The psychology and physiology of stress. New York: Plenum.

Iso-Ahola, S. E. (1997). A psychological analysis of leisure and health. In J. T. Haworth (Ed.), Work, leisure and well-being (pp. 131-144). London: Routledge.

Iso-Ahola, S. E., \& Park, C. J. (1996). Leisure-related social support and self-determination as buffers of stress-illness relationships. Journal of Leisure Research, 28, 169-187.

Jackson, S. E., \& Schuler, R. S. (1985). A meta-analysis and conceptual critique of research on role ambiguity and role conflict in work settings. Organizational Behavior and Human Performance, 33, 1-21.

Kahn, R. L., \& Byosiere, P. (1992). Stress in organizations. In M. D. Dunnette \& L. M. Hough (Eds.), Handbook of industrial and organizational psychology (2nd ed., Vol. 3, pp. 571-650). Palo Alto, CA: Consulting Psychologists Press.

Kahn, R. L., Wolfe, D. M., Quinn, R. P., Snoek, J. D., \& Rosenthal, R. A. (1964). Organizational stress: Studies in role confict and ambiguity. New York: Wiley.

Karasek, R., \& Theorell, T. (1990). Healthy work: Stress, productivity and the reconstruction of working life. New York: Basic Books.

Kirkcaldy, B. D., \& Cooper, C. L. (1993). The relationship between work stress and leisure style: British and German managers. Human Relations, 46, 669-680.

Kleiber, D., Larson, R., \& Csikszentmihalyi, M. (1986). The experience of leisure in adolescence. Journal of Leisure Research, 18, 169-176.

Knauth, P., Kiesswetter, E., Ottman, W., Karvonen, M. J., \& Rutenfranz, J. (1983). Time-budget studies of policemen in weekly or swiftly rotating shift systems. Applied Ergonomics, 14, 247-252.

Kubey, R. W., \& Csikszentmihalyi, M. (1990). Television as escape: Subjective experience before an evening of heavy viewing. Communication Reports, 3, 92-100.

Lee, R. T., \& Ashforth, B. E. (1996). A meta-analytic examination of the correlates of the three dimensions of job burnout. Journal of Applied Psychology, 81, 123133.

Leitner, M. J., \& Leitner, S. F. (1989). Leisure enhancement. Binghampton, NY: Howorth.
Lundberg, U., Marberg, B., \& Frankenhaeuser, M. (1994) The total workload of male and female white collar workers as related to age, occupational level and number of children. Scandinavian Journal of Psychology, 35, 315-327.

Mardberg, B., Lundberg, U., \& Frankenhaeuser, M. (1991). The total workload of parents employed in white-collar jobs: Construction of a questionnaire and a scoring system. Scandinavian Journal of Psychology, 32, 233-239.

Meijman, T. F., \& Mulder, G. (1998). Psychological aspects of workload. In P. J. D. Drenth \& H. Thierry (Eds.), Handbook of work and organizational psychology: Vol. 2. Work psychology (pp. 5-33). Hove, England: Psychology Press.

Meijman, T. F., Mulder, G., \& Van Dormolen, M. (1992). Workload of driving examiners: A psychophysiological field study. In H. Kragt (Ed.), Enhancing industrial performances (pp. 245-260). London: Taylor \& Francis.

Ministerie van Onderwijs, Cultuur en Wetenschappen. (1999). Onderwijs Cultuur en Wetenschappen in kerncijfers [Education, culture, and science in numbers]. The Hague, The Netherlands: Author.

Palmore, E:, \& Luikart, C. (1972). Health and social factors related to life satisfaction. Journal of Health and Social Behavior, 13, 68-80.

Petruzzello, S. J., Landers, D. M., Hatfield, B. D., Kubitz, K. A., \& Salazar, W. (1991). A meta-analysis on the anxiety-reducing effects of acute and chronic exercise. Sports Medicine, 11, 143-182.

Rasbash, J., \& Woodhouse, G. (1996). MLn. London: University of London, Institute of Education.

Repetti, R. L. (1989). Effects of daily workload on subsequent behavior during marital interaction: The roles of social withdrawal and spouse support. Journal of Personality and Social Psychology, 57, 651-659.

Robinson, J. P. (1999). The time-diary method. In W. E. Pentland, A. S. Harvey, M. P. Lawton, \& M. A. McColl (Eds.), Time use research in the social sciences (pp. 47-89). New York: Kluwer.

Schalk, R., Keunen, A., \& Meijer, T. (1995). Warr's schalen voor welzijn en mentale gezondheid: Factorstructuur en betrouwbaarheid [Warr's scales for measuring well-being and mental health: Factor structure and reliability]. Gedrag en Organisatie, 8, 116-127.

Schaufeli, W. B., Daamen, J., \& Van Mierlo, H. (1994). Burnout among Dutch teachers: An MBI-validity study. Educational and Psychological Measurement, 54, 803812.

Semmer, N. (1984). Streßbezogene Tätigkeitsanalyse [Stress-oriented analysis of work: Psychological studies on the analysis of stress at work]. Weinheim, Germany: Beltz.

Semmer, N. (1996). Individual differences, work stress and health. In M. J. Schabracq, J. A. M. Winnubst, \& C. L. Cooper (Eds.), Handbook of work and health psychology (pp. 51-86). Chichester, England: Wiley.

Semmer, N., Zapf, D., \& Dunckel, H. (1999). Instrument zur Stressbezogenen Tätigkeitsanalyse (ISTA) [Instrument for stress-oriented analysis of work (ISTA)]. In H. Dunckel (Ed.), Handbuch psychologischer Arbeitsanalyseverfahren [Handbook of psychological work analysis instruments] (pp. 179-204). Zürich: vdf Hochschulverlag an der ETH.

Smith, R. E., Leffingwell, T. R., \& Ptacek, J. T. (1999). Can 
people remember how they coped? Factors associated with discordance between same-day and retrospective reports. Joumal of Personality and Social Psychology, $76,1050-1061$

Snijders, T. A. B., \& Bosker, R. J. (1999). Multilevel analysis. An introduction to basic and advanced multilevel modeling. London: Sage.

Sonnentag, S. (2000), Assessing daily recovery activities: First experiences with a diary method (Technical report). Konstanz, Germany, University of Konstanz.

Spector, P. (1986). Perceived control by employees: A meta-analysis of studies concerning autonomy and participation at work. Human Relations, 39, 1005-1016.

Spurgeon, A., \& Cooper, C. L. (2000). Working time, health and performance. In C. L. Cooper \& I. T. Robertson (Eds.), International review of industrial and organizational psychology (Vol. 15, pp. 189-222). Chichester, England: Wiley.

Stanton-Rich, H. M., \& Iso-Ahola, S. E. (1998). Burnout and leisure. Joumal of Applied Social Psychology, 28, 1931-1950.

Staw, B. M., Sutton, R. I., \& Pelled, L. H. (1994). Employee positive emotion and favorable outcomes at the workplace. Organization Science, 5, 51-71.

Stone, A. A., Schwartz, J. E., Neale, J. M., Shiffman, S., Marco, C. A., Hickcox, M., Paty, J., Porter, L. S., \& Cruise, L. J. (1998). A comparison of coping assessed by ecological momentary assessment and retrospective recall. Journal of Personality and Social Psychology, 74, $1670-1680$

Totterdell, P., Spelten, E., Smith, L., Barton, J., \& Folkard, S. (1995). Recovery from work shifts: How long does it take? Journal of Applied Psychology, 80, 43-57.

Van der Doef, M., \& Maes, S. (1999). The job demandcontrol (-support) model and psychological well-being: A review of 20 years of empirical research. Work \& Stress, 13, 87-114.
Veenhoven, R. (1984). Data-book of happiness. Dordrecht, the Netherlands: Reidel.

Viswesvaran, C., Sanchez, J. I., \& Fisher, J. (1999). The role of social support in the process of work stress: A meta-analysis. Journal of Vocational Behavior, 54, $314-$ 334.

Wall, T. D., Jackson, P. R., Mullarkey, S., \& Parker, S. K. (1996). The demands-control model of job strain: A more specific test. Joumal of Occupational and Organizational Psychology, 69, 153-166.

Wankel, L. M., \& Berger, B. G. (1990). The psychological and social benefits of sport and physical activity. Journal of Leisure Research, 22, 167-182.

Warr, P. B. (1987). Work, unemployment, and mental health. Oxford, England: Oxford University Press.

Warr, P. (1990). The measurement of well-being and other aspects of mental health. Journal of Occupational Psychology, 63, 193-210.

Wells, K., Stewart, A., Hays, R., Burnam, M., Rogers, W., Daniels, M., Berry, S., Greefield, S., \& Ware, J. (1989). The functioning and well-being of depressed patients: results from the Medical Outcome Study. Journal of the American Medical Association, 262, 914-919.

Westman, M., \& Eden, D. (1997). Effects of a respite from work on burnout: Vacation relief and fade-out. Journal of Applied Psychology, 82, 516-527.

Yeung, R. R. (1996). The acute effects of exercise on mood state. Journal of Psychosomatic Research, 40, 123-141.

Zapf, D. (1993). Stress-oriented analysis of computerized office work. European Work and Organizational Psychologist, 3, 85-100.

Zapf, D., Dormann, C., \& Frese, M. (1996). Longitudinal studies in organizational stress research: A review of the literature with reference to methodological issues. Journal of Occupational Health Psychology, 1, 145-169. 


\section{Appendix}

\section{Multilevel Analysis Procedure}

Bryk and Raudenbush (1992) and Snijders and Bosker (1999) provided comprehensive introductions into multilevel analysis. In short, multilevel analysis is a data analysis method for hierarchically structured datasets and takes into account within-group and between-groups variance. In the case of the present study, in which the "groups" are the individual persons, the method takes into account withinperson and between-person variance. For specific datasets such as the present one, multilevel analysis is superior to ordinary least square regression analysis, which assumes independence of observations. Multilevel analysis, however, allows for dependent observations within the higher level data structure (i.e., participants in the present study; Snijders \& Bosker, 1999).

Multilevel analysis comprises separate models for the various data levels. In the present case with two levels, the model at Level 1 (day level) expresses each person's wellbeing before going to sleep formally as

$$
\begin{aligned}
Y_{t i} & =\beta_{0 i}+\beta_{1 i}(\text { well-being after work })_{t i}+ \\
& +\beta_{2 i}(\text { work-related activities })_{t i}+ \\
& +\beta_{3 i}(\text { low-effort activities) })_{r i}+ \\
& +\beta_{4 i}(\text { household activities })_{t i}+ \\
& +\beta_{5 i}(\text { social activities })_{t i}+ \\
& \left.+\beta_{6 i} \text { (physical acivities) }\right)_{t i}+\mathrm{e}_{t i}
\end{aligned}
$$

where $t$ refers to Day $t$ and $i$ refers to Person $i$. Thus, this models specifies each person's well-being as a function of this person's well-being after work, his or her involvement in the five leisure time activities, an intercept $\beta_{\mathrm{O} i}$, and an error term $\mathrm{e}_{t i}$.

At Level 2 (person level), the model consists of

$$
\begin{aligned}
\boldsymbol{\beta}_{0 i}= & \gamma_{00}+\gamma_{01}(\text { gender })_{i}+\gamma_{02}(\text { age })_{i}+ \\
& \left.+\gamma_{03} \text { (children }\right)_{i}+\gamma_{04}(\text { control at work })_{i}+ \\
& \left.+\gamma_{05} \text { (time pressure }\right)_{i}+ \\
& \left.+\gamma_{06} \text { (uncertainty }\right)_{i}+u_{0 i}
\end{aligned}
$$

$$
\begin{aligned}
& \beta_{1 i}=\gamma_{10} \\
& \beta_{2 i}=\gamma_{20} \\
& \beta_{3 i}=\gamma_{30} \\
& \beta_{4 i}=\gamma_{40} \\
& \beta_{5 i}=\gamma_{50} \\
& \beta_{6 i}=\gamma_{60} .
\end{aligned}
$$

When combining Equations (1) and (2) the final model results as

$$
\begin{aligned}
\mathrm{Y}_{t i}= & \gamma_{00}+\gamma_{01}(\text { gender })_{i}+\gamma_{02}(\text { age })_{i}+ \\
& +\gamma_{03}(\text { children })_{i}+\gamma_{04}(\text { control at work })_{i}+ \\
& \left.+\gamma_{05}(\text { time pressure })_{i}+\gamma_{06} \text { (uncertainty }\right)_{i}+ \\
& +\gamma_{10}(\text { well-being at the end of the work day })_{t i}+ \\
& +\gamma_{20}(\text { work-related activities })_{t i}+ \\
& \left.+\gamma_{30} \text { (household activities }\right)_{t i}+ \\
& +\gamma_{40}{\text { (low-effort activities })_{t i}+}+ \\
& +\gamma_{50}{\text { (social activities })_{t i}+}+ \\
& \left.+\gamma_{60} \text { (physical activities }\right)_{t i}+ \\
& +\mathrm{u}_{0 i}+\mathrm{e}_{t i} .
\end{aligned}
$$

Note that in this model only the intercept parameter of the Level 1 model $\beta_{0 i}$ is assumed to vary at Level 2 (i.e., to differ across individuals). The other parameters (i.e., $\beta_{1 i}$ to $\boldsymbol{\beta}_{6 i}$ ) are assumed to be the same for all individuals.

The part with the $\gamma$-coefficients represents the fixed effects in the model, and $\mathrm{u}_{0 i}$ and $\mathrm{e}_{t i}$ represent the random part of the model. The significance of the fixed effects can be tested with the $t$-test statistic by calculating the ratio of the estimated coefficients to their standard error. Additionally, the model fit of competing models can be tested by a likelihood ratio test.

Received June 7, 2000

Revision received November 6, 2000 Accepted January 10, 2001 